TITLE:

\title{
Thermoelectric properties and crystallographic shear structures in titanium oxides of the Magneli phases
}

\author{
AUTHOR(S):
}

Harada, Shunta; Tanaka, Katsushi; Inui, Haruyuki

\section{CITATION:}

Harada, Shunta ...[et al]. Thermoelectric properties and crystallographic shear structures in titanium oxides of the Magneli phases. JOURNAL OF APPLIED PHYSICS 2010, 108(8): 083703.

\section{ISSUE DATE:}

2010-10

URL:

http://hdl.handle.net/2433/147186

\section{RIGHT:}

Copyright 2010 American Institute of Physics. This article may be downloaded for personal use only. Any other use requires prior permission of the author and the American Institute of Physics. The following article appeared in JOURNAL OF APPLIED PHYSICS108, 083703 (2010) and may be found at http://link.aip.org/link/APPLAB/v96/i25/p252901_s1 


\title{
Thermoelectric properties and crystallographic shear structures in titanium oxides of the Magnèli phases
}

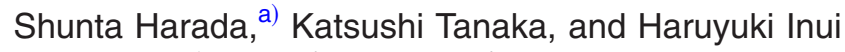 \\ Department of Materials Science and Engineering, Kyoto University, Sakyo-ku, Kyoto 606-8501, Japan
}

(Received 13 May 2010; accepted 30 August 2010; published online 18 October 2010)

\begin{abstract}
The thermoelectric properties of Magnèli phase titanium oxides $\operatorname{Ti}_{n} \mathrm{O}_{2 n-1}(n=2,3, \ldots)$ have been investigated, paying special attention to how the thermoelectric performance can be altered by changing the microstructure. Dense polycrystalline specimens with nominal composition of $\mathrm{TiO}_{2-x}$ $(x=0.05,0.10,0.15$, and 0.20$)$ prepared by conventional hot-pressing are all identified to be one of the Magnèli phases, in which crystallographic shear planes are regularly introduced according to the oxygen deficiency. Electrical conduction is n-type for all specimens and the carrier concentration increases with the increase in the oxygen deficiency. The values of lattice thermal conductivity, on the other hand, decrease with the increase in the oxygen deficiency, which can be attributed to phonon scattering at the crystallographic shear plane. The largest value of thermoelectric figure of merit $Z, 1.6 \times 10^{-4} \mathrm{~K}^{-1}$ was obtained at $773 \mathrm{~K}$ for the hot-pressed specimen of $\mathrm{TiO}_{1.90}$. (C) 2010 American Institute of Physics. [doi:10.1063/1.3498801]
\end{abstract}

\section{INTRODUCTION}

Thermoelectric materials have been receiving great interest in recent years due to their potential applications such as in electric power generation by waste heat and in cooling system. ${ }^{1}$ The efficiency of thermoelectric materials is evaluated by the dimensionless figure of merit $Z T=\alpha^{2} T / \rho \lambda$ where $Z, \alpha, \rho, \lambda$, and $T$ correspond to the figure of merit, Seebeck coefficient, electrical resistivity, thermal conductivity, and absolute temperature, respectively. Thermal conductivity consists of two components; the phonon (lattice) contribution $\left(\kappa_{l}\right)$ and the carrier contribution $\left(\kappa_{e}\right)$. While $\kappa_{e}$ is related to electrical resistivity through Wiedemann-Franz law, $\kappa_{l}$ is independent of carrier concentration. Therefore, low lattice thermal conductivity is beneficial to thermoelectric performance. There may be many different ways to reduce lattice thermal conductivity. One way to achieve this is to introduce crystal lattice defects such as point defect and grain boundary that act as sources for phonon scattering. ${ }^{2-4}$ However, many of them sometimes act as sources for carrier scattering as well, which leads to the degradation of thermoelectric performance. This indicates that some special crystal lattice defects that act as sources for phonon scattering but not as sources for carrier scattering have to be introduced for thermoelectric materials to achieve the high performance.

In the present study, we pay special attention to crystallographic shear structures introduced in some reduced $\mathrm{TiO}_{2}$ (rutile) of homologous series of the Magnèli phase. Homologous series of Magnèli phase titanium oxides are expressed with $\mathrm{Ti}_{n} \mathrm{O}_{2 n-1}(n=2,3, \ldots)$ (Ref. 5) and they form so-called crystallographic shear structures, in which dense planar defects are regularly introduced in the mother rutile structure with their spacing depending on the oxygen deficiency, ${ }^{6}$ as will be described in detail in the next section. According to Bartholomew and Fankl ${ }^{7}$ who investigated systematically the

\footnotetext{
${ }^{\text {a)} E l e c t r o n i c ~ m a i l: ~ h a r a d a . s h u n t a @ t 02 . m b o x . m e d i a . k y o t o-u . a c . j p . ~}$
}

electrical properties of single crystals of Magnèli phase titanium oxides, electrical conduction of Magnèli phase titanium oxides is metallic and the value of electrical resistivity decreases with the increase in the oxygen deficiency. This may clearly indicate that the crystallographic shear plane in Magnèli phase titanium oxides does not act significantly as sources for carrier scattering. If the crystallographic shear plane acts as sources for phonon scattering, we may expect the high thermoelectric performance for Magnèli phase titanium oxides. Although there are some recent reports on thermoelectric properties for some reduced $\mathrm{TiO}_{2},{ }^{8,9}$ the thermoelectric properties of Magnèli phase titanium oxides have not been thoroughly understood yet in terms of structureproperty relations.

In the present study, we investigate the thermoelectric properties of Magnèli phase titanium oxides $\mathrm{Ti}_{n} \mathrm{O}_{2 n-1}$, paying special attention to how the thermoelectric performances are affected by the presence of crystallographic shear planes.

\section{CRYSTALLOGRAPHIC SHEAR STRUCTURES IN MAGNĖLI PHASE TITANIUM OXIDES}

Magnèli et al. ${ }^{5}$ and co-workers started a systematic investigation of some oxides of transition metal such as titanium, vanadium, molybdenum, and tungsten by $\mathrm{x}$-ray diffraction (XRD). As a result, they confirmed the existence of homologous compounds expressed by $\operatorname{Ti}_{n} \mathrm{O}_{2 n-1}(n=2,3, \ldots)$ and predicted that these structures could be all derived from the rutile structure as the mother structure. Later, Wadsley proposed the structure principle of these structures (called crystallographic shear structure ${ }^{10}$ ), describing how these structures are derived from the mother structure, as follows: ${ }^{6}$

(1) The mother structure is divided into blocks periodically parallel to a crystallographic plane called shear plane [Fig. 1(a)].

(2) Blocks are translated relatively each other by a certain vector called shear vector [Fig. 1(b)]. 
(a)

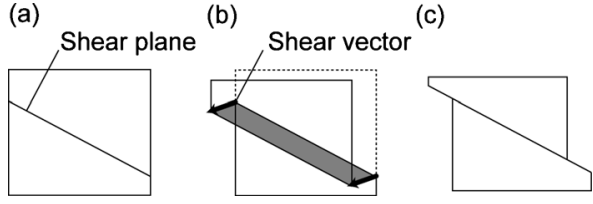

FIG. 1. Schematic illustration of crystallographic shear operation.

(3) The overlapping parts, if generated by (2), are removed [Fig. 1(c)].

They identified that the crystallographic shear plane and vector for titanium oxides $\mathrm{Ti}_{n} \mathrm{O}_{2 n-1}(n=2,3, \ldots, 10)$ are $(121)_{\text {rutile }}$ and $1 / 2[0 \overline{1} 1]_{\text {rutile, }}$, respectively. ${ }^{6,11,12}$ Later, Bursill et $a l^{13}$ have reported that the crystallographic shear plane changes to $(132)_{\text {rutile }}$ when $n$ in $\mathrm{Ti}_{n} \mathrm{O}_{2 n-1}$ is greater than 10 . The crystallographic shear structures formed with the shear operations described above are schematically illustrated in Fig. 2. The shear vector corresponds to a vector connecting a position of oxygen ion with another in the $b c$-plane, thus resulting in no disturbance in the oxygen arrangement. However, the titanium arrangement is disturbed since the shear vector moves titanium ions in the octahedron formed by six oxygen ions to the interstitial octahedral positions (Fig. 2). As a result, the oxygen deficiency occurs on the shear plane (Fig. 2) and homologous series of Magnèli phase titanium oxides with various $\mathrm{Ti} / \mathrm{O}$ ratios are formed by changing the spacing of the crystallographic shear plane.

In the rutile type structure, the stacking sequence of $\{121\}$ and $\{132\}$ planes, both of which can be the shear plane, is described as-BAB BAB BAB-, where $\mathbf{A}$ is a plane consisting of titanium ions only $(\mathbf{A}=\mathrm{Ti})$ and $\mathbf{B}$ is a plane consisting of oxygen ions only $(\mathbf{B}=\mathrm{O})$. The shear operation corresponds to the removal of pure oxygen planes of the $\mathbf{B}$-type in a periodic manner. If the shear plane is introduced every $n$ A planes, the stacking sequence changes to-BAB $\mathbf{B A}^{*}$ BAB- $\left({ }^{*}\right.$ denotes the position of the shear plane) and the overall composition is described as the sum of $n \mathbf{A}$ planes and $(2 n-1) \mathbf{B}$ planes so as to be $\mathrm{Ti}_{n} \mathrm{O}_{2 n-1}$. The atomic arrangement in $\mathrm{Ti}_{6} \mathrm{O}_{11}$, one of the Magnèli phase formed with $n=6$ is schematically illustrated in Fig. 3, where the oxygen deficiency and the disturbance of the titanium ion arrangement is evident to occur at the crystallographic shear plane.

When the crystallographic shear planes are introduced in (a)

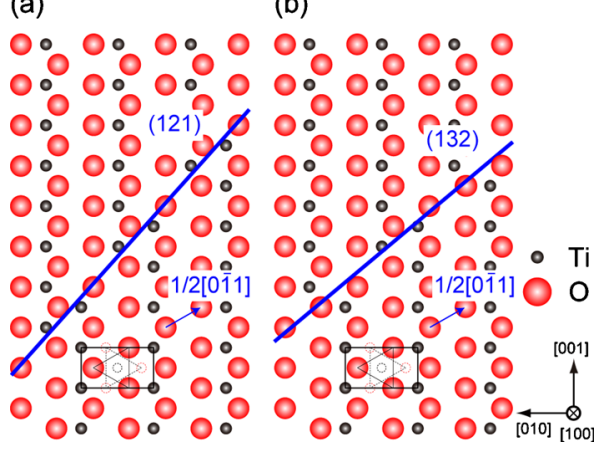

FIG. 2. (Color online) Schematic illustration of crystallographic shear structure of Magnéli phase titanium oxide. (a) Crystallographic shear operation $(121)_{\text {rutile }} 1 / 2[0 \overline{1} 1]_{\text {rutile }}$ and (b) (132) rutile $1 / 2[0 \overline{1} 1]_{\text {rutile. }}$

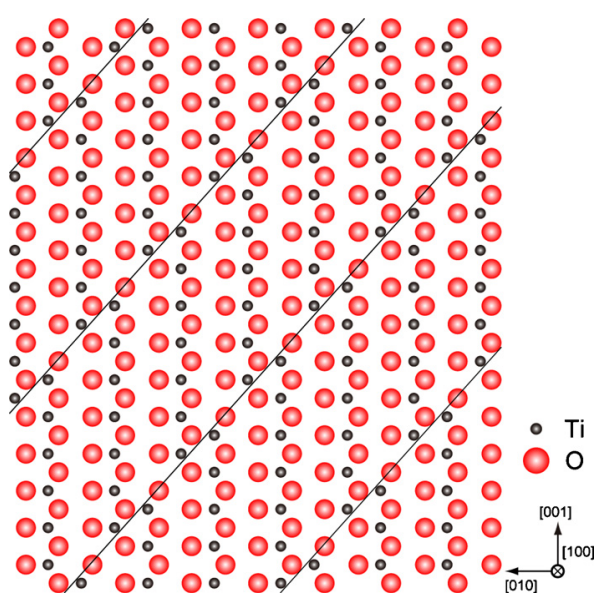

FIG. 3. (Color online) (a) Schematic illustration of ideal structure of $\mathrm{Ti}_{6} \mathrm{O}_{11}$ $(n=6)$ crystallographic shear structure in Magnéli phase titanium oxide.

the mother rutile structure, one can anticipate the occurrence of a series of superlattice reflection spots along the reciprocal lattice vector corresponding to the shear plane [either along $\boldsymbol{g}(121)_{\text {rutile }}$ or along $\left.\boldsymbol{g}(132)_{\text {rutile }}\right]$ at positions corresponding to $n$ (the periodicity to introduce the crystallographic shear planes). The electron diffraction pattern expected for $\mathrm{Ti}_{6} \mathrm{O}_{11}$ formed by introducing the crystallographic shear planes parallel to (121) rutile with $n=6$ is depicted in Fig. 4. The incident beam direction is chosen to be so as to include the reciprocal lattice vector corresponding to the shear plane in the diffraction pattern. Six equally spaced superlattice reflection spots are observed between the transmitted beam spot and that corresponding to the shear plane (121) rutile. Thus, once the incident beam direction is chosen so that the reciprocal lattice vector corresponding to the shear plane is included in the diffraction pattern, the identification of the Magnèli phases $\left(\mathrm{Ti}_{n} \mathrm{O}_{2 n-1}\right)$ can be readily made by noting the positions (number) of a series of superlattice reflection spots along the reciprocal lattice vector corresponding to the shear plane. We utilize this method for the identification of the Magnèli phases in the present study.

\section{EXPERIMENTAL PROCEDURE}

Commercial $\mathrm{TiO}_{2}$ and $\mathrm{TiO}$ powders weighted in proper ratios were mixed in ethanol solvent by planetary-type ballmilling for $12 \mathrm{~h}$. After drying, the mixtures were sealed in a

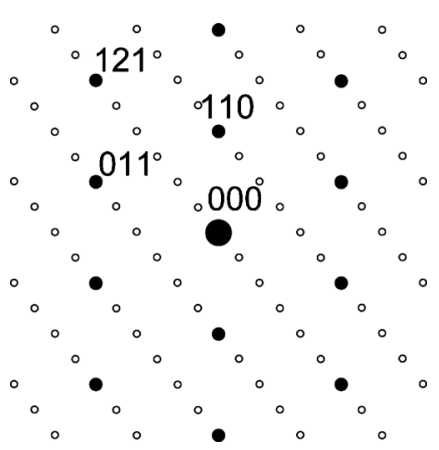

FIG. 4. Schematic illustration of electron diffraction pattern taken from $\mathrm{Ti}_{6} \mathrm{O}_{11}$. The zone axis is $[1 \overline{1} 1]$. A series of super spots are aligned along $g(121)$. 
TABLE I. Condition of hot-pressing, identified phases from XRD, and average grain size of prepared specimens.

\begin{tabular}{lcccccc}
\hline \hline & \multicolumn{3}{c}{ HP conditions } & & \\
\cline { 2 - 4 } $\begin{array}{l}\text { Nominal } \\
\text { composition }\end{array}$ & $\begin{array}{c}\text { Temperature } \\
(\mathrm{K})\end{array}$ & $\begin{array}{c}\text { Time } \\
(\mathrm{min})\end{array}$ & $\begin{array}{c}\text { Pressure } \\
(\mathrm{MPa})\end{array}$ & $\begin{array}{c}\text { Phase } \\
\text { assemblage }\end{array}$ & $\begin{array}{c}\text { Average } \\
\text { grain size } \\
(\mu \mathrm{m})\end{array}$ \\
\hline $\mathrm{TiO}_{2.00}$ & 1123 & 30 & 50 & $\mathrm{TiO}_{2}$ & 0.51 \\
$\mathrm{TiO}_{1.95}$ & 1373 & 20 & 50 & & $\ldots$ & 0.93 \\
$\mathrm{TiO}_{1.90}$ & 1473 & 10 & 50 & $\mathrm{Ti}_{8} \mathrm{O}_{15}$ & 0.90 \\
$\mathrm{TiO}_{1.85}$ & 1473 & 10 & 50 & $\mathrm{Ti}_{5} \mathrm{O}_{9}+\mathrm{Ti}_{6} \mathrm{O}_{11}$ & 1.12 \\
$\mathrm{TiO}_{1.80}$ & 1473 & 10 & 50 & & $\mathrm{Ti}_{4} \mathrm{O}_{7}$ & 1.26 \\
\hline \hline
\end{tabular}

silica tube partially backfilled with Ar gas and were annealed at $1473 \mathrm{~K}$ for $12 \mathrm{~h}$ to produce $\mathrm{TiO}_{2-x}$ powders with $x$ $=0.05,0.10,0.15$, and 0.20 through solid-state reaction. Then, $\mathrm{TiO}_{2-x}$ powders were sintered by conventional hotpressing in a carbon die under the conditions described in Table I. Since significant reduction is noted as the change in color to black for $\mathrm{TiO}_{2}$ after sintering even the sintering temperature was considerably decreased, the $\mathrm{TiO}_{2}$ sintered body was annealed again at $1073 \mathrm{~K}$ for $4 \mathrm{~h}$ in air to oxidize.

Phase identification was made by powder XRD and electron diffraction, and microstructures were examined by transmission electron microscopy (TEM). Measurements of electrical resistivity and Seebeck coefficient were made with our ULVAC ZEM-2 apparatus in the temperature range from 323 to $773 \mathrm{~K}$. Measurements of thermal conductivity were carried out at room temperature by the static method. Values of thermal conductivity above room temperature were evaluated with the thermal diffusivity measured by the laser flash method and the reported values of specific heat for rutile. ${ }^{14,15}$

\section{RESULTS}

\section{A. Phase identification and microstructures}

Figure 5 shows XRD patterns from hot-pressed specimens of $\mathrm{TiO}_{2-x}$ with $x=0,0.05,0.10,0.15$, and 0.20 . Diffraction peaks from all these specimens, except for that with $x=0.05$, are almost all consistently indexed as those from

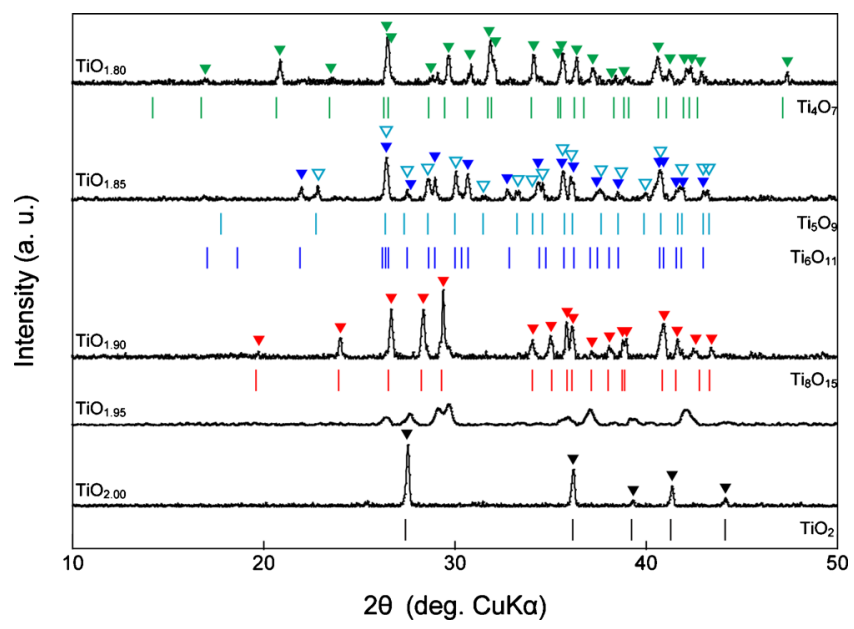

FIG. 5. (Color online) XRD patterns from hot-pressed specimens of $\mathrm{TiO}_{2-x}$ $(x=0,0.05,0.10,0.15$, and 0.20$)$ together with the reported XRD patterns from Magnéli phase $\mathrm{Ti}_{n} \mathrm{O}_{2 n-1}$ (Ref. 6).

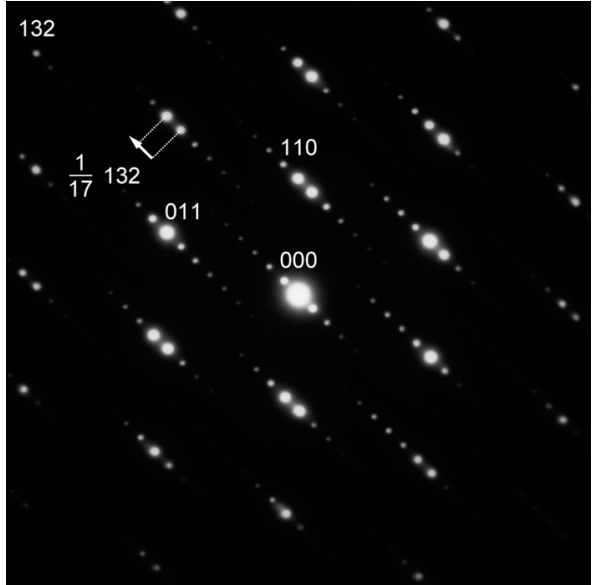

FIG. 6. Selected area electron diffraction pattern from hot-pressed specimen of $\mathrm{TiO}_{1.95}$ along the $[1 \overline{1} 1]$ zone axis.

one of titanium oxides of the Magnèli phase previously identified by Andersson et al. ${ }^{5}$ Phases identified for each of hotpressed specimens of $\mathrm{TiO}_{2-x}$ by XRD are summarized in Table I. While essentially only a single phase is identified for hot-pressed specimens of $\mathrm{TiO}_{2.00}, \mathrm{TiO}_{1.90}$, and $\mathrm{TiO}_{1.80}$, the hot-pressed specimen of $\mathrm{TiO}_{1.85}$ is observed to consist of two phases, $\mathrm{Ti}_{5} \mathrm{O}_{9}$ and $\mathrm{Ti}_{6} \mathrm{O}_{11}$. When judged from the chemical formulae of these identified Magnèli phases, the actual oxygen contents of these hot-pressed specimens of $\mathrm{TiO}_{1.90}$, $\mathrm{TiO}_{1.85}$ and $\mathrm{TiO}_{1.80}$ are all lower than their nominal compositions, indicating the occurrence of reduction during hotpressing. XRD peaks from the hot-pressed specimen of $\mathrm{TiO}_{1.95}$ do not coincide with those of any of titanium oxides of the Magnèli phase ever reported. This is because of the fact that phase identification by XRD has been so far made only for titanium oxides, $\mathrm{Ti}_{n} \mathrm{O}_{2 n-1}$ of the Magnèli phase with $n=2$ to $10 .^{5}$ We thus utilized electron diffraction for phase identification of the hot-pressed specimen of $\mathrm{TiO}_{1.95}$. A selected area electron diffraction pattern taken from the hotpressed specimen of $\mathrm{TiO}_{1.95}$ along $[1 \overline{1} 1]_{\text {rutile }}$ is shown in Fig. 6 . The line of superlattice reflection spots are directed approximately $(132)_{\text {rutile }}$ and the interval of the superlattice reflection spots correspond to about 17 times as long as the $(132)_{\text {rutile }}$ interplanar spacing. This fact indicates that the composition of the hot-pressed specimen of $\mathrm{TiO}_{1.95}$ is approximately $\mathrm{Ti}_{17} \mathrm{O}_{33}\left(\mathrm{TiO}_{1.941}\right)$.

TEM microstructures of hot-pressed specimens of $\mathrm{TiO}_{2-x}$ with $x=0,0.05,0.10,0.15$, and 0.20 are depicted in Fig. 7. Electron diffraction analyses confirm the results of phase identification by XRD tabulated in Table I. Although some planar faults are observed in some grains, many of them are identified to be twin boundaries. The grain size is evaluated for each of specimens and the results obtained are also tabulated in Table I. The grain size does not differ significantly from each other for all the specimens of the Magnèli phases. Figure 8 shows a high-resolution TEM image of the $\mathrm{Ti}_{6} \mathrm{O}_{11}$ Magnèli phase observed in a hot-pressed specimen of $\mathrm{TiO}_{1.85}$. Being consistent with the attached electron diffraction pattern, the crystallographic shear structure is formed by introducing the shear planes parallel to (121) rutile every six pure titanium planes. Of importance to note in Fig. 

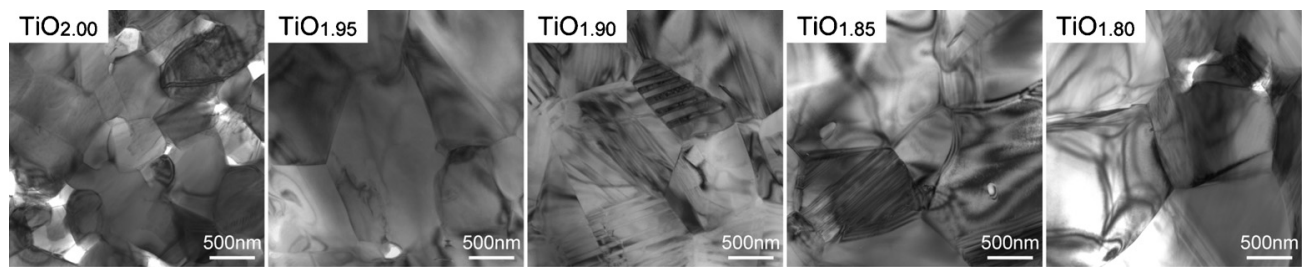

FIG. 7. TEM bright field images of hot-pressed specimens of $\mathrm{TiO}_{2-x}$ with $x=0,0.05,0.10,0.15$, and 0.20 .

8 is that the disturbance of the periodicity to introduce the shear planes is hardly observed, which is consistent with the sharpness of superlattice reflection spots in the diffraction pattern. The disturbance of the shear plane periodicity is hardly observed also for other specimens of the Magnèli phases.

\section{B. Thermoelectric properties}

Values of electrical resistivity for hot-pressed specimens of $\mathrm{TiO}_{2-x}$ with $x=0.05,0.10,0.15$, and 0.20 are plotted in Fig. 8(a) as a function of temperature. The temperature dependence of electrical resistivity varies with the ratio of $\mathrm{O} / \mathrm{Ti}$ of specimens, i.e., with the value of $x$ in $\mathrm{TiO}_{2-x}$. The value of electrical resistivity decreases with the increase in temperature for $\mathrm{TiO}_{1.95}$ and $\mathrm{TiO}_{1.90}$, while it increases with the increase in temperature for $\mathrm{TiO}_{1.80}$. In contrast, the value of electrical resistivity for $\mathrm{TiO}_{1.85}$ is virtually independent of temperature. Over the whole temperature range investigated, the values of electrical resistivity decreases as the value of $x$ in $\mathrm{TiO}_{2-x}$ increases, i.e., as the oxygen content decreases. This indicates that electrical conduction of $\mathrm{TiO}_{2-x}$ of the Magnèli phase is metallic when the carrier concentration is high (i.e., when the $x$ value is large, which is consistent with the results obtained by Bartholomew and Fankl, ${ }^{7}$ whereas it is semiconducting when the carrier concentration is low.

Values of Seebeck coefficient for hot-pressed specimens of $\mathrm{TiO}_{2-x}$ with $x=0.05,0.10,0.15$, and 0.20 are plotted in Fig. 8(b) as a function of temperature. The values of Seebeck coefficient for all specimens are negative in sign (n-type conduction). The absolute value of Seebeck coefficient increases as the oxygen content decreases over the whole temperature range investigated. While the value of Seebeck coefficient for $\mathrm{TiO}_{1.95}$ is virtually temperature independent, it increases with the increase in temperature for other specimens.

The values of thermal conductivity for hot-pressed specimens of $\mathrm{TiO}_{2-x}$ with $x=0,0.05,0.10,0.15$, and 0.20

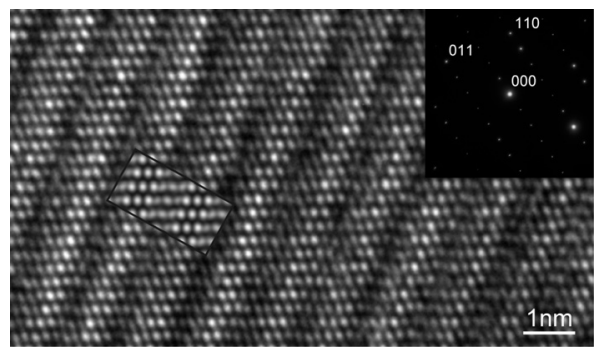

FIG. 8. A high-resolution TEM image of the $\mathrm{Ti}_{6} \mathrm{O}_{11}$ Magnèli phase observed in the hot-pressed specimen of $\mathrm{TiO}_{1.85}$. A inset is the simulated images of $\mathrm{Ti}_{6} \mathrm{O}_{11}$ Magnèli phase (simulation condition: $\Delta f=-32 \mathrm{~nm}, t=30 \mathrm{~nm}$ ) using the reported atomic coordinates of $\mathrm{Ti}_{6} \mathrm{O}_{11}$ (Ref. 11). measured by the static method at room temperature are tabulated in Table II together with the estimated values of the lattice contribution $\left(\lambda_{\text {lattice }}\right)$ to thermal conductivity. The values of $\lambda_{\text {lattice }}$ were estimated according to the WiedemannFranz approximation with the use of following equation: ${ }^{16}$

$$
\lambda_{\text {lattice }}=\lambda_{\text {total }}-\lambda_{\text {electron }}=\lambda_{\text {total }}-\frac{L_{0} T}{\rho}\left(\frac{k_{\mathrm{B}}}{e}\right)^{2},
$$

where $\lambda_{\text {total }}$ and $\lambda_{\text {electron }}$ stand, respectively, for total and lattice contribution $\left(\lambda_{\text {lattice }}\right)$ to thermal conductivity, and $k_{\mathrm{B}}, e$, $L_{0}$ stand, respectively, for Boltzmann's constant, electron charge, and a constant usually take a value of $\pi^{2} / 3$ for metallic conductors. The value of $\lambda_{\text {lattice }}$ decreases as the oxygen content decreases. Values of $\lambda_{\text {total }}$ and $\lambda_{\text {lattice }}$ are plotted, respectively, in Figs. 9(a) and 9(b) as a function of temperature. As seen in Fig. 9(b), the value of $\lambda_{\text {lattice }}$ systematically decreases as the oxygen content decreases over the whole temperature range investigated.

\section{DISCUSSION}

\section{A. Thermal conductivity}

The lower value of thermal conductivity of hot-pressed stoichiometric $\mathrm{TiO}_{2}$ when compared to rutile single crystal $(6-8 \mathrm{~W} \mathrm{~m} / \mathrm{K})$ (Ref. 17) is due to phonon scattering by grain boundaries. This is further confirmed by the fact that the value of thermal conductivity of hot-pressed stoichiometric $\mathrm{TiO}_{2}$ at room temperature increases from $5.18 \mathrm{~W} / \mathrm{K} \mathrm{m}$ for the average grain size of $0.51 \mu \mathrm{m}$ to $5.88 \mathrm{~W} / \mathrm{K} \mathrm{m}$ for the grain size of $4.2 \mu \mathrm{m}$ after further annealing at $1473 \mathrm{~K}$ for $72 \mathrm{~h}$ in air (Fig. 10. Of significance to note, however, is that although the average grain sizes for hot-pressed specimens of off-stoichiometric $\mathrm{TiO}_{2-x}$, all of which are of the of Magnèli phases, are generally larger than that for the hot-pressed specimen of stoichiometric $\mathrm{TiO}_{2}$ (Table I), the values of thermal conductivity are considerably smaller for off-stoichiometric $\mathrm{TiO}_{2-x}$ than for stoichiometric $\mathrm{TiO}_{2}$ and that the value of thermal conductivity for hot-

TABLE II. Values of thermal conductivity and lattice thermal conductivity measured by the static method at room temperature.

\begin{tabular}{lcc}
\hline \hline $\begin{array}{l}\text { Nominal } \\
\text { composition }\end{array}$ & $\begin{array}{c}\text { Thermal } \\
\text { conductivity } \\
(\mathrm{W} / \mathrm{K} \mathrm{m})\end{array}$ & $\begin{array}{c}\text { Lattice thermal } \\
\text { conductivity } \\
\text { (W/K m) }\end{array}$ \\
\hline $\mathrm{TiO}_{2.00}$ & 5.18 & 5.18 \\
$\mathrm{TiO}_{1.95}$ & 2.74 & 2.70 \\
$\mathrm{TiO}_{1.90}$ & 2.39 & 2.28 \\
$\mathrm{TiO}_{1.85}$ & 2.60 & 2.20 \\
$\mathrm{TiO}_{1.80}$ & 3.15 & 2.04 \\
\hline \hline
\end{tabular}




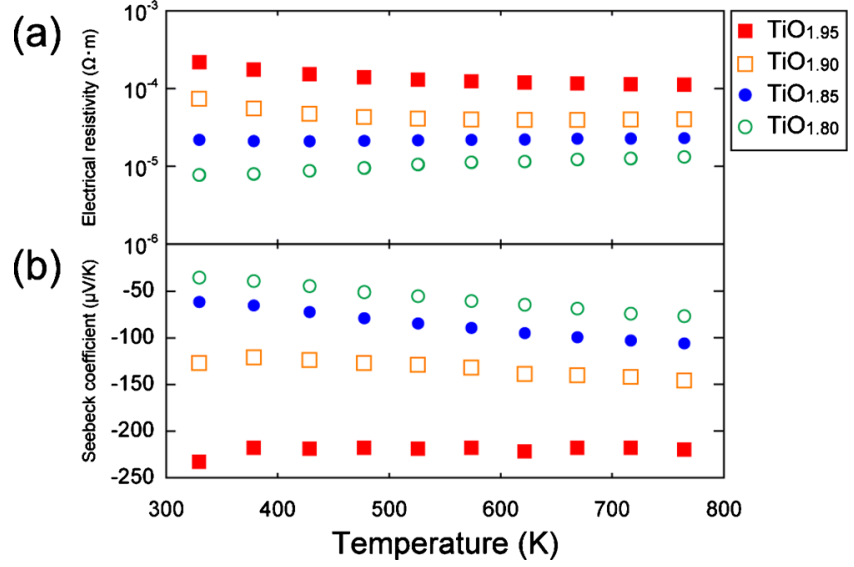

FIG. 9. (Color online) Temperature dependence of electrical resistivity (a) and Seebeck coefficient (b) for the hot-pressed specimens of $\mathrm{TiO}_{2-x}$.

pressed specimens of off-stoichiometric $\mathrm{TiO}_{2-x}$ tends to decrease with the increase in the oxygen deficiency (Table II). Indeed, the value of lattice thermal conductivity of $\mathrm{Ti}_{4} \mathrm{O}_{7}$ (the hot-pressed specimen with $x=0.20$ ) decreases by more than $60 \%$ at room temperature and by about $40 \%$ at $773 \mathrm{~K}$, when compared to stoichiometric $\mathrm{TiO}_{2}$. The decrease in lattice thermal conductivity with the increase in the oxygen deficiency observed for off-stoichiometric $\mathrm{TiO}_{2-x}$ may be concluded to be due to enhanced phonon scattering at the crystallographic shear plane, when judged from the variation in lattice thermal conductivity with the density of crystallographic shear planes (reciprocals of the spacing of crystallographic shear planes) as shown in Fig. 11. Both at room temperature and $773 \mathrm{~K}$, the value of lattice thermal conductivity decreases with the increase in the density of the crystallographic shear plane. Assuming the Debye model, the mean free path for phonons can be evaluated for hot-pressed specimens of $\mathrm{TiO}_{2-x}$ with the use of the following equation and observed lattice thermal conductivity:

$$
\lambda_{\text {lattice }}=\frac{1}{3} C_{p} \rho v l,
$$

where $C_{p}$ and $v$ stand, respectively, for specific heat and sound velocity $\left[\left(6.91 \times 10^{3} \mathrm{~m} / \mathrm{s}\right.\right.$ for $\mathrm{TiO}_{2}$ (Ref. 18)], and $l$ is

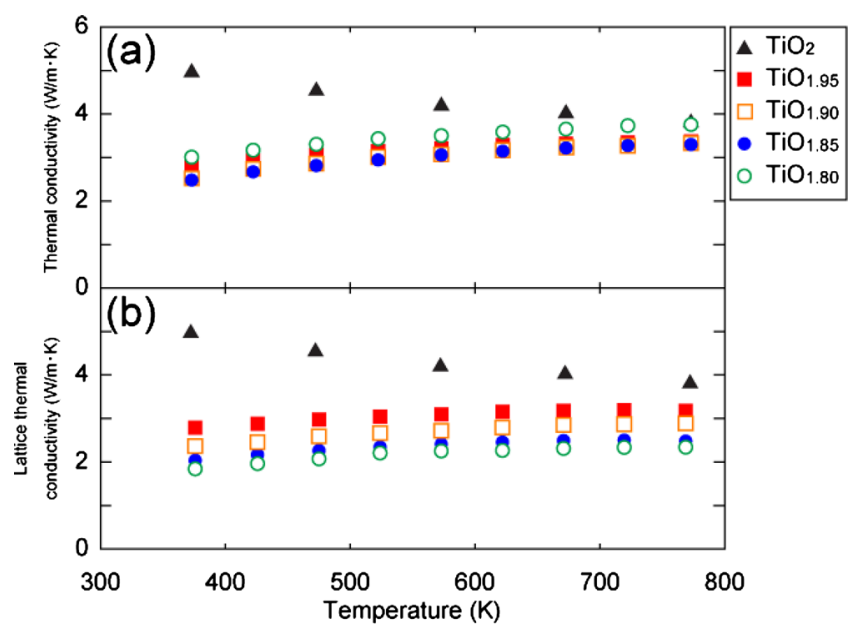

FIG. 10. (Color online) Temperature dependence of thermal conductivity (a) and lattice thermal conductivity (b) for the hot-pressed specimens of $\mathrm{TiO}_{2-x}$.

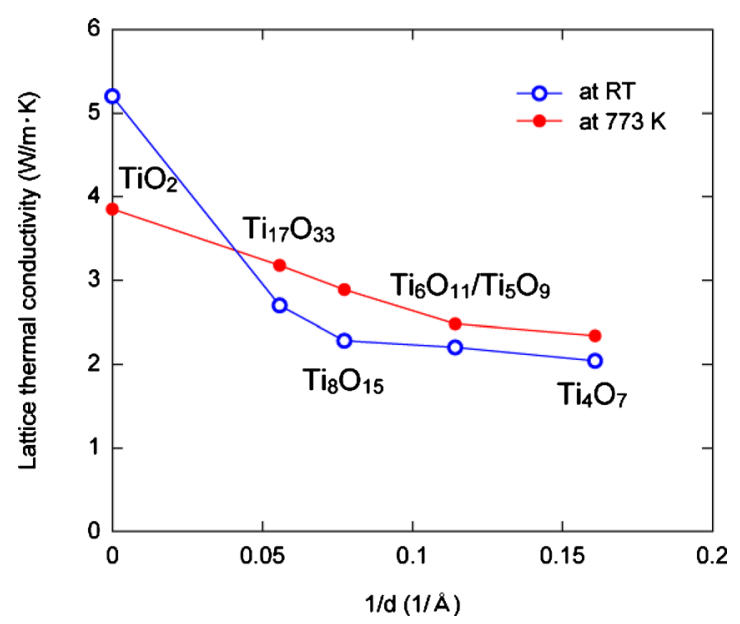

FIG. 11. (Color online) Shear plane spacing dependence of lattice thermal conductivity for Magnéli phase titanium oxides at room temperature and $773 \mathrm{~K}$.

the mean free path for phonons. The value of phonon mean free path evaluated at room temperature for stoichiometric $\mathrm{TiO}_{2}$ is $0.8 \mathrm{~nm}$, which is comparable to the spacings $(0.5-2$ $\mathrm{nm})$ for crystallographic shear planes observed for hotpressed specimens of $\mathrm{TiO}_{2-x}$. It is therefore obvious that the crystallographic shear planes in titanium oxides of the Magnèli phases can act as sources for phonon scattering. Not only the interatomic distances between titanium and neighboring oxygen ions but also their configurations (coordinations) in the vicinity of the crystallographic shear plane are somewhat different from those in the mother (rutile) structure, which may lead to enhanced phonon scattering at the crystallographic shear plane, and thereby the reduced thermal conductivity in Magnèli phase titanium oxides.

\section{B. Electrical conductivity}

Assuming that the number of delocalized electrons is identical to that of conduction electrons, the electron mobility can be evaluated for hot-pressed specimens of $\mathrm{TiO}_{2-x}$ with the following equation:

$$
\rho=\frac{1}{n e \mu},
$$

where $\rho, n$, and $\mu$ stand, respectively, for electrical resistivity, electron charge, and electron mobility. As tabulated in Table III, the electron mobility for hot-pressed specimens of $\mathrm{TiO}_{2-x}$ increases with the increase in the oxygen deficiency. It is therefore evident that the crystallographic shear plane does not act as significant sources for electron scattering,

TABLE III. Reported conduction electron density (Ref. 19) and evaluated electron mobility for some hot-pressed specimens of $\mathrm{TiO}_{2-x}$.

\begin{tabular}{lcc}
\hline \hline $\begin{array}{l}\text { Nominal } \\
\text { composition }\end{array}$ & $\begin{array}{c}\text { Conduction electron density } \\
\left(\mathrm{g} / \mathrm{cm}^{2}\right)\end{array}$ & $\begin{array}{c}\text { Electron mobility } \\
\left(\mathrm{cm}^{2} / \mathrm{V} \mathrm{s}\right)\end{array}$ \\
\hline $\mathrm{TiO}_{1.90}$ & $4.60 \times 10^{27}$ & 0.184 \\
$\mathrm{TiO}_{1.85}$ & $9.90 \times 10^{27}$ & 0.289 \\
$\mathrm{TiO}_{1.80}$ & $1.54 \times 10^{28}$ & 0.526 \\
\hline \hline
\end{tabular}




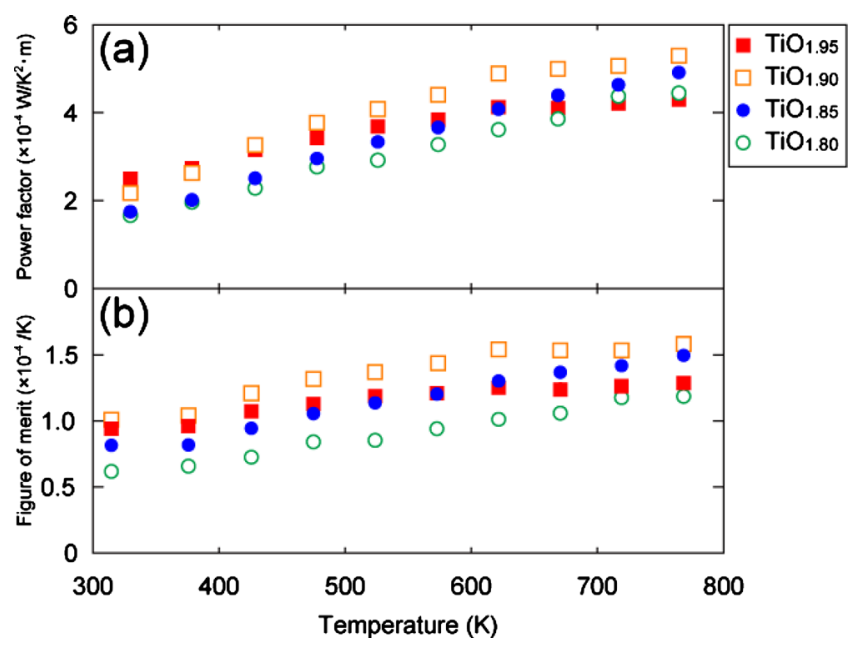

FIG. 12. (Color online) Values of power factor $\left(\alpha^{2} / \rho\right)$ and figure of merit $\left(\alpha^{2} / \rho \lambda\right)$ obtained for hot-pressed specimens of $\mathrm{TiO}_{2-x}$.

unlike for phonon scattering. This is a favorable characteristic for thermoelectric materials.

\section{Thermoelectric performance}

Values of power factor $\left(\alpha^{2} / \rho\right)$ and figure of merit $\left(\alpha^{2} / \rho \lambda\right)$ obtained for hot-pressed specimens of $\mathrm{TiO}_{2-x}$ are plotted, respectively, in Figs. 12(a) and 12(b) as a function of temperature. The maximum value $\left(5.3 \times 10^{-4} \mathrm{~W} / \mathrm{K}^{2} \mathrm{~m}\right)$ of thermoelectric power factor is obtained at $773 \mathrm{~K}$ for the specimen with $x=0.10$. The maximum $Z$ value (thermoelectric figure of merit) of $1.6 \times 10^{-4} \mathrm{~K}^{-1}$ is obtained also at 773 $\mathrm{K}(Z T=0.13)$ for the specimen with $x=0.10$. Although the maximum $Z$ value obtained in the present study for Magnèli phase titanium oxides are not surprisingly high when compared to nonoxide thermoelectric materials such as $\mathrm{Bi}_{2} \mathrm{Te}_{3}$, $\mathrm{SiGe}$, and so on, it is comparable to those obtained for other nonoriented polycrystalline oxides so far reported such as $\mathrm{Y}$ doped $\mathrm{SrTiO}_{3}{ }^{20} \mathrm{ZnO}-\mathrm{In}_{2} \mathrm{O}_{3}$ (Ref. 21), and so on. Similar crystallographic shear structures have also been observed in $\mathrm{TiO}_{2}$ doped with trivalent cations such as $\mathrm{Cr}$ and Fe. ${ }^{22-24} \mathrm{In}$ view of the fact that the introduction of the crystallographic shear plane causes the reduction in thermal conductivity without significantly affecting electric conduction, the thermoelectric performance of Magnèli phase titanium oxides $\mathrm{TiO}_{2-x}$ may be further improved by introducing the crystallographic shear plane in a controlled manner with the use of trivalent cations.

\section{CONCLUSION}

The thermoelectric properties of Magnèli phase titanium oxides $\mathrm{Ti}_{n} \mathrm{O}_{2 n-1}$ have been investigated with the use of dense polycrystalline specimens prepared by conventional hotpressing. The results obtained are summarized as follows:

(1) All off-stoichiometric specimens are of the Magnèli phases, in which crystallographic shear planes are regularly introduced with the periodicity depending on the oxygen deficiency.

(2) Electrical conduction is n-type for all specimens and the carrier concentration increases with the increase in the oxygen deficiency. The values of electrical resistivity and Seebeck coefficient therefore decrease with the increase in the oxygen deficiency. The value of lattice thermal conductivity, on the other hand, decreases the increase in the oxygen deficiency. When judged from the oxygen deficiency dependence of electrical resistivity and lattice thermal conductivity, the crystallographic shear plane is concluded to act as sources for phonon scattering but not for carrier scattering.

(4) The largest value of thermoelectric figure of merit $Z$, $1.6 \times 10^{-4} \mathrm{~K}^{-1}$ was obtained at $773 \mathrm{~K}$ for the hotpressed specimen of $\mathrm{TiO}_{1.90}$.

\section{ACKNOWLEDGMENTS}

This work was partly supported by Grant-in-Aid for Scientific Research (A) and (B) from the Ministry of Education, Science and Culture and Technology (MEXT), Japan (Grant Nos. 21246101 and 21360337) and in part by the Global COE (Center of Excellence) Program on International Center for Integrated Research and Advanced Education in Material Science from the MEXT, Japan. One of the authors (S. Harada) greatly appreciates the supports from Grant-in-Aid for JSPS Fellows.

${ }^{1}$ T. M. Tritt, Science 283, 804 (1999).

${ }^{2}$ L. Tewordt and T. Wolkhausen, Solid State Commun. 70, 839 (1989).

${ }^{3}$ D. M. Rowe and V. S. Shukla, J. Appl. Phys. 52, 7421 (1981).

${ }^{4}$ J. Callaway and H. C. von Baeyer, Phys. Rev. 120, 1149 (1960).

${ }^{5}$ J. S. Andersson, B. Collèn, U. Kuylenstierna, and A. Magnèli, Acta Chem. Scand. 11, 1641 (1957).

${ }^{6}$ J. S. Anderson and B. G. Hyde, J. Phys. Chem. Solids 28, 1393 (1967).

${ }^{7}$ R. F. Bartholomew and D. R. Fankl, Phys. Rev. 187, 828 (1969).

${ }^{8}$ Y. Lu, M. Hirohashi, and K. Sato, Mater. Trans. 47, 1449 (2006).

${ }^{9}$ W. R. Thurber and A. J. Mante, Phys. Rev. 139, A1655 (1965).

${ }^{10}$ L. A. Bursill, Proc. R. Soc. London, Ser. A 311, 267 (1969).

${ }^{11}$ S. Andersson, Acta Chem. Scand. 14, 1161 (1960).

${ }^{12}$ Y. Le Page and P. Strobel, J. Solid State Chem. 44, 273 (1982).

${ }^{13}$ L. A. Bursill and B. G. Hyde, Acta Crystallogr., Sect. B: Struct. Crystallogr. Cryst. Chem. 27, 210 (1971).

${ }^{14}$ D. C. Lynch and D. E. Bullard, Metall. Mater. Trans. B 28, 447 (1997).

${ }^{15}$ J. S. Arthur, J. Appl. Phys. 21, 732 (1950).

${ }^{16}$ G. D. Mahan and M. Bartkowiak, Appl. Phys. Lett. 74, 953 (1999).

${ }^{17}$ Thermophysical Properties of Matter, edited by Y. S. Touloukian, (IFI/ Plenum, New York, 1970).

${ }^{18}$ R. G. Mcqueen, J. C. Jamieson, and S. P. Marsh, Science 155, 1401 (1967).

${ }^{19}$ J. F. Houlihan, W. J. Danley, and L. N. Mulay, J. Solid State Chem. 12, 265 (1975).

${ }^{20}$ H. Obara, A. Yamamoto, C. H. Lee, K. Kobayashi, A. Matsumoto, and R. Funahashi, Jpn. J. Appl. Phys., Part 2 43, L540 (2004).

${ }^{21}$ H. Ohta, W. S. Seo, and K. Koumoto, J. Am. Ceram. Soc. 79, 2193 (1996).

${ }^{22}$ S. Andersson, A. Sundholm, and A. Magnèli, Acta Chem. Scand. 13, 989 (1959).

${ }^{23}$ R. M. Gibb and J. S. Anderson, J. Solid State Chem. 4, 379 (1972).

${ }^{24}$ R. M. Gibb and J. S. Anderson, J. Solid State Chem. 5, 212 (1972). 